\title{
The phenomenon of synaesthesia in phantom limbs - therapeutic treatment
}

\author{
Zanna Fiodorenko-Dumas', Malgorzata Paprocka-Borowicz', Ilias Dumas', Rajmund Adamiec² \\ 'Department of Physiotherapy, Wroclaw Medical University, Poland \\ ${ }^{2}$ Department of Angiology, Hypertension and Diabetology, Wroclaw Medical University, Poland
}

\begin{abstract}
Phantom pains, appearing as a consequence of the amputation of a limb, have their source in the work of human brain. Many authors claim that the development and intensification of these sensations are connected to the neuroplasticity of the brain. Difficulties in the estimation of the circumstances, as well as patients' ineffective attempts to palliate the pain, make the problem a vitally important issue. Pharmacotherapy is still a dominant and popular form of treatment.

This paper serves to describe the causes of phantom pains and to discuss the possible treatment techniques, namely physiotherapy and unconventional therapeutic methods.

The effectiveness of physiotherapy depends mainly on the accurate choice of the physiotherapeutic method or concrete treatment. The reactions of tissues to a stimulus and the obtaining desirable reaction of the human organism allow for achieving proper homeostasis and limiting pain. There are many areas of medicine where physiotherapy has proved to be successful, and its usefulness in the management of the phantom sensations should be also assessed.
\end{abstract}

Key words: phantom pain, physiotherapy, synaesthesia, nervous system

Acta Angiol 2015; $21,1: 25-29$

\section{Introduction}

The term synaesthesia denotes the ability to perceive the world with the use of senses. It is a state in which the reception of stimuli by a single type of receptors results in stimulation of other senses. In a healthy human, it usually appears in the area of association of i.e. a colour with the sensation of cold or warmth, or a sound with the sensation of calmness, softness. It turns out that people who have their lower limb amputated experience the grapheme-colour type of synaesthesia, where the image of a particular sign conjures up the impression of a colour connoted to this sign [I].
The aim of this work is to discuss the mechanism of phantom pains and to illustrate particular phenomena that are often observed in patients after the amputation of a limb. While attempting to explain the phenomena that occur in a human organism, neuroplasticity of the brain should be given special consideration. In a number of cases, it constitutes a denominator for patients' feelings and sensations. Physiotherapeutic methods are significant elements in fighting the pain. Literature on both the theoretical basis and clinical practice suggest the possibility of using traditional rehabilitation methods, as well as methods that occur relatively seldom and are not very popular. 


\section{Aetiopathogenesis of the phantom pains}

Amputation is not only a physical damage - post-amputation process concerns the whole organism. Suffering, emotional and situational circumstances, necessity to accept the new body - all of these factors influence the emergence and maintenance of the phantom symptom. Approximately $80 \%$ of individuals after amputation experience phantom sensations. The following mechanisms should be paid particular attention: peripheral mechanisms - where a haematoma is created as a consequence of cutting of the nerve at the level of residual limb; central mechanisms - where functional cortex is reorganized; psychological mechanisms connected to subjective experiencing of the body [2].

Literature states that phantom pains in an amputated limb or in areas with sensory deprivation (cut-off sense of touch) may be palliated by blocking a specific compound in the brain. Normally, three different groups of nerve cells participate in the process of pain reception. Firstly, a group of sensory neurons receives pain stimuli from the damaged tissue and conveys the sensory information to the spinal cord. The information is further conveyed by other neurons to the brain structure thalamus and then transferred by the last cell group to the primary sensory cortex. After the information is processed, the pain can be felt [3].

Commonly, in the physiology the pain is one of sensation types, the so-called nociceptive sensation. Human organism uses it to obtain information about noxious agents which pose a threat to its biophysical balance and mobilize numerous defence mechanisms. Pain may also be treated as a psychosomatic phenomenon, the so-called allogeneic brain syndrome. This state is characterized by symptoms such as depressed mood, cognitive function disorders, increased irritability, sleeping disorders, and increase in patient's concentration on the symptoms of the disease. Focus on painful sensations and experiencing the pain with fear, as a disease, intensifies the pain felt by a patient. Inappropriate therapeutic treatment is the cause of the pain becoming a chronic condition causing changes in the process of conveying impulses by the nerve cells. The nervous system remembers the pain, which impedes the process of chronic pain treatment and delurks with the reoccurrence of the symptoms [4].

It is currently assumed that patients may experience three kinds of sensations: phantom, which is non-painful feeling of the amputated limb; residual limb pain connected to the left fragment of amputated extremity; and phantom pain in the non-existing part of body. According to Finnoff, approximately $80 \%$ of individuals who have their limb amputated, experience phantom pains, while Dobrogowski states that the number is ca. $50 \%$.
Duration of the pain depends on a particular case; it may last from few months to few years. Phantom pains are usually psychogenic pains, which means that there is no organic reason for the pain and the patients feel the pain of the same character and in the same localisation as they used to in the period of the illness prior to amputation. There are numerous theories which explain the origins of phantom pain. Here are some of them:

- peripheral theory - where the central nervous system misinterprets the impulses from the residual limb, as coming from the amputated limb;

- spinal theory - where the damaging stimulus reaches the spinal cord via fast-transmitting myelinated fibres type $A$ and non-myelinated fibres type C;

- central theory - as a consequence of constant supply of sensor stimuli, a virtual limb is attached to the central nervous system;

- vessel theory - reduced blood supply to the residual limb intensifies phantom pain;

- neuromatrix theory - proposes that the phantom pain is the effect of reflection between the thalamus and the cortex, which may function either with or without sensory innervations [4].

The residual limb takes its final shape after 6 to 8 weeks following the surgery. The muscles above the residual limb disappear and reduce their amount, which causes emaciation and constriction along the residual limb. Blood vessels are retracted and filled with thrombi, nerves undergo degeneration process, thinning of the bone structure occurs over the months, which leads to bone porosity and is conducive to frequent bone fracture [5].

Phantom pain is an unpleasant feeling, usually occurring a few days after the amputation. The patients feel as if they still had the amputated limb and were able to even move it.

There are phantom pains of kinaesthetic character, which involve the volume, position and moves of the phantom limb. They occur more frequently in the patients after tight amputation than in those after below-the-knee amputation. The pains may differ with respect to intensity, frequency, time of duration and character. They may be shooting, contraction-like, stabbing, burning, squeezing. Patients describe them as similar to knife-cutting in the early post-amputation stage and stabbing, turning into squeezing, hot and contraction-like pains.

Arising of the pain may indicate the nervous system's ability to learn and remember pain. Permanence is a significant feature of cell memory. It turns out that an originally active structure that provides certain symptoms, such as pain, is no longer clinically active after the treatment. However, the features of a prior change of activity in a tissue can be recognized after 
many years in the oversensitivity, tingling, etc. Such state allows distinguishing cause-effect relationships in some particular structures with some other anatomical structures, which enables the therapist to identify the current reason for patient's pain. Another characteristic of tissue memory is the readiness to receive dysfunction information, as well as normalization information. It is called access of afferent activity [6, 7].

Most of the patients with phantom limb get the impression of the ability to move it or feel that the limb is stiff. According to Ramachandran, the state of paralysis can be explained by the fact that each time patients attempt to move the phantom limb, they receive feedback information (visually or via proprioception), that the extremity does not move.

Preservation of such information in neurons responsible for sensation follows the Hebb's rule [8].

Ramachandran's latest research concerns the occurrence of synaesthesia mechanism. There are two theories explaining the phenomenon. According to Simon Baron-Cohen, there may be additional connections in the brains of the individuals experiencing synaesthesia, linking the areas which are normally disjointed. The other theory states that the number of synaptic connections in the brain is equal in each case, and the intermingling of received experiences derives from the imbalance between curbing and soothing the impulses in the brain [9].

\section{Therapeutic treatment}

Handling with the pain engages both medical and psychological measures. Physiotherapy, which uses a set of stimuli treatment methods based on tissues' reaction to stimuli, is an essential element of the treatment. Selecting a stimulus which results in a specific, desired reaction of the organism is a key to achieve the expected result. Applying a series of the same physiotherapeutic factors improves the effect of homeostasis corrective mechanism and increases the level of its reposition. Depending on the type of energy connected to a certain treatment, adequate response of the organism is created.

Regarding the state of physical weakening, J.H. Schultz's autogenic training, C. Simonton's steered visualization methods or bodywork techniques may be applied. The purpose of these methods is release of pain, improved contact with patient's own body, increase of the level of mobilization, energy and self-resistance of the body. All the actions aim at reaching a mental state that will be helpful in the process of recovering. Here are the indications for phantom pains and sensations psychotherapy: patients shall be prepared for amputation and the nature of phantom pains shall be explained to them; patients shall be provided with measures allowing them to verbalize phantom sensations; finally, each patient shall be treated in an individual way. Shultz's autogenic training is a psychosomatic method the result of which is psychophysical release. It raises work productivity and capability to concentrate and memorize things, as well as it improves the quality of sleeping and enables a person to relax [2, 10].

Hypnosis is another method which requires, however, examining the patient's condition before its application, in order to ascertain that there are no contraindications for using hypnosis. These include low blood pressure, reoccurring episodically respiratory and circulatory system dysfunctions and psychoses. There is always a threat coming from a hypnotherapy session done in a wrong, incorrect way which is often a result of hypnotherapist's incompetence. Effects of hypnosis are the most significant in palliating the unpleasant sensations. Shallow hypnosis is much similar to relaxation. By using the right suggestions, positive physiological changes in a patient with anxiety can be achieved. The changes include interim blood pressure lowering, breath and heart rate decreasing. If conducted in the right way, hypnosis may be also useful in phantom pain treatment [10].

Transdermal electric nerve stimulation (TENS) has a positive effect on chronic pain syndrome treatment with adequate, carefully chosen low frequency currents. Three types of transdermal electric nerve stimulation can be found in literature: the first one is conventional, with current frequency from $10-200 \mathrm{~Hz}$, current intensity from 25-30 mA and duration time $50 \mathrm{~ms}$. The patient to whom it is applied should feel tingling, not pain or muscle spasms. The other type of TENS is similar to acupuncture (APL-TENS), using impulses of low frequency (from 0.5-8) and duration time approximately $0.2 \mathrm{~ms}$, unipolar or bipolar, mainly rectangular. The last type is hyperstimulation TENS, which uses a series of impulses, usually 2 impulses repeating one to five times a second, frequency from $10-100 \mathrm{~Hz}$ and maximal permissible intensity on trigger points. The entire procedure lasts from I5-20 minutes. The intensity reaches pain threshold and its pain-killing effect is connected to endorphin production.

The literature confirms the TENS currents effectiveness on treating phantom pains. They use impulse current of low frequency from $\mathrm{I}-150 \mathrm{~Hz}$, approximating to physiological currents. It decreases the pain sensation by lowering the number of impulses sent from sensory nerves to the cortex. The shape of this impulse causes intensification of endorphin release to bloodstream. Endorphins are neurohormones produced by the organism, which have an effect similar to morphine's. It should be stressed that TENS may be effective wher- 
ever dysfunction of muscles or nerves occurs, providing those muscles or nerves can be reached through the skin. There are no side effects of using TENS and the method does not interact with other medicaments. It is used as causal treatment in the area of pain or along the disordered nerve. Selected muscle or a group of muscles may be actuated by using TENS without causing damage to the skeleton, respiratory and circulatory systems. In phantom pains, the electrodes should be put in the area of the most intense pain or it source, it may be put around the same dermatome, myotome, sclerotome, which the pain sensation is received from, and above spinal nerve roots. It covers lumbosacral spine and distal fragment of residual limb [ I , 12].

Ultrasound is another physiotherapeutic method which can decrease the phantom pains, subjectively in certain cases. While using ultrasound therapy, thermal, mechanical and physicochemical effects shall be expected, with biological effect resultant of the above three. The character of ultrasound reaction may be local, primary, secondary or general, which is a consequence of nerve-humoral and central compensatory mechanisms. Ultrasound has a very broad effect, which results in pain-killing reaction. It shall be mentioned that ultrasounds create good conditions for production of new capillaries in tissues with chronic ischaemia and for release of growth factors from macrophages. It is particularly important in amputations resulting from capillary diseases. Dosages depend on the chosen method (static or dynamic). The first one, with intensity $0.2-0.5 \mathrm{~W} / \mathrm{cm}^{2}$ and duration 7 minutes, is chosen in the case of rest pain [12].

The literature states that a positive effect may be achieved by using whirlpool bathing, a kind of underwater massage of lower limb. Special bathtubs equipped with a device activating water gyre movement are used for this procedure. The procedure takes 20-30 minutes. Water temperature is $35-40^{\circ} \mathrm{C}$. The purpose of whirlpool bathing is achieving local limb congestion, reducing oedema and countermeasuring against venous congestion, as well as achieving pain-killing and muscle-relaxing effect [13].

According to the patients, physical treatment, if applied regularly to the residual limb, released the pain sensations. It should not be forgotten, however, that most of the unpleasant feelings result from the brain's memory of the previous events.

Even an adult's brain is extremely malleable, which means that there is a set of complex, interacting nets remaining in a state of dynamic balance with the brain environment [13].

Some patients claim that they can suggestively feel the movements of phantom limbs. This is probably caused by monitoring of the reafferent signals, which come from motoric commands and are sent to phantom limb. Monitoring takes place in the cerebellum and parietal lobe. With time, phantom limb becomes "frozen", perhaps as a consequence of constant lack of visual impulse and of proprioceptive confirmation of response to movement command $[14,15]$.

\section{Alternative therapeutic techniques}

Embedding and processing of the information, which take place in the brain, may significantly restrict or intensify the pain. Conquering the learned behaviours is a crucial task. Ramachandran developed the so-called mirror therapy. His research proved that it is possible to break the vicious circle of pain and disuse by remapping of primary somatosensory cortex, as a result of using visual feedback mechanism.

In patients with phantom pains and sensations, providing the visual feedback as a substitute of lacking proprioceptive feedback may decrease the pain, enabling the patient to experience the phantom as 'more alive'. Premotor cortex plays a crucial role. When there is a lack of somatosensory feedback, visual feedback may serve to reintroduce the flow of information from the posterior parietal cortex to premotor cortex. Engagement of premotor cortex or reorganization of motor program may decrease the pain and ease the movement of the limbs. Mirror therapy may be used to obtain visual feedback. Patient's limbs, put in a container, are separated with a mirror in a sagittal (medial) plane. In a way, the patient gets deceived and assured that the disordered limb moves without effort or pain. This is a crucial element in the rehabilitation process [16].

Working with the mirrors enables to distinguish three different implications. One allows palliating the pain emerging form improper position of the phantom limb and the spasms. The other indicates the hierarchical-module brain model, which is based on the interactions between various levels and modules. The last one suggests that the image of the body, although appears to be stable and invulnerable, is just a temporary internal construction created by human brain for the interim period in order to pass on the genes on to the next generation [17, 18].

Another interesting way of fighting with phantom limb pain is the mechanism of synaesthesia type grapheme-colour, introduced by Ramachandran, where the image of a particular sign indicates a connoted colour [I].

\section{Conclusions}

The sensation of an amputated limb does not necessarily have to be painful. It is experienced by some people 
as itching, feeling of warmth or cold. In such cases, the feeling is called a phantom sensation. There is also phantom pain, described in various ways, for instance as knife-cutting, stinging or tingling. Medicine remains helpless in case of such feelings. Despite providing the patients with painkillers and antidepressants, the pain is only soothed for some time, after which it reappears even more intensified. Phantom pain disorganizes the life of a person whose limb has been amputated, changes its every aspect. It may cause sleeping disorders, problems at work, in social life and everyday home activities. The pain may also lead to loss of appetite, which consequently results in the overall body weakening.

Untreated pain may lead to depression and development of the sense of hopelessness. People tend to think that phantom pain is an unavoidable consequence of loss of the extremity. This is where the numerous programs devoted to effective fighting with phantom pains (including pharmacotherapy, psychotherapy and physiotherapy) have their origins. Effectiveness of each and every of them depends individually on the patient; however failure to try any of the mentioned forms will be a serious mistake. Nurturing and developing of the feeling of suffering may be extremely exhausting and at the same time may drive the patient into a state of alienation from the environment $[19,20]$.

\section{References}

I. Hubbard EM, Arman AC, Ramachandran VS, Boynton GM (2005) Individual differences among grapheme-color synesthetes: brain-behavior correlations. Neuron; 46: 975-985.

2. Chodak M (2003) Fenomen bólów, odczuć i kończyn fantomowych w świetle współczesnej wiedzy i psychoterapii. Wykład wygłoszony na II Spotkaniu Otwartych UNICORN 2003 - Żyj z chorobą nowotworową. Kraków 8.03.2003.

3. Holiday PJ (1991) Early postoperative care of the amputee. In: Kostulik JP (ed) Amputation surgery and rehabilitation. Churchill Livingstone, New York.
4. Dziak A (1983) Amputacje i wyłuszczenia. In: Gruca A (ed) Chirurgia ortopedyczna. Volume 2. PZWL, Warszawa.

5. Dziak A (1987) Bolesny kikut. Polski Tygodnik Lekarski; XLII.

6. Dobrogowski J (200I) Przetrwały ból pooperacyjny. Ból; 2: 23-28.

7. Sandkuhler J (200I) Uczenie się i pamięć w drogach bólowych. Ból; 2: 6-13.

8. MacLachlan M, McDonald D, Waloch J (2004) Mirror treatment of lower limb phantom pain: a case study. Disabil Rehabil; 26: 90I-904.

9. Miles CA, Miles CJ (2009) Skull of Minotaurasaurus ramachandrani a new Cretaceous ankylosaur from the Gobi Desert. Current Science; 96: 65-70.

10. Kinarski R (2002) Kompendium rehabilitacji i fizjoterapii. Urban \& Partner, Wroclaw, 67.

11. Gessier M, Struppler A, Oettinger B (198I) Treatment of phantom pain by TENS of the stump, the limb contralateral to the stump, and of the other extremities. Springer-Verlag, New York.

12. Taradaj J, Sieroń A, Jarzębski M (2010) Fizykoterapia w praktyce. Elamed, Katowice.

13. Paprocka-Borowicz M, Pozowski A, Murawska-Ciałowicz E (2005) Leczenie doznań fantomowych i bólów fantomowych u pacjentów po amputacji kończyny dolnej. Fizjoterapia Polska; 5: 169-173.

14. Katz J, Melzack R (1990) Pain „memories” in phantom limbs: review and clinical observations. Pain; 43: 319.

15. Ramachandran VS, Rogers-Ramachandran D (1996) Synaesthesia in phantom limbs induced with mirrors. Proc Biol Sci; 256: 377-386.

16. Ramachandran VS, Rogers-Ramachandran D (2000) Phantom limbs and neural plasticity. Arch Neurol; 57: 317-320.

17. McCabe CS, Haigh RC, Blake DR (2008) Mirror visual feedback for the treatment of complex regional pain syndrome (type I). Curr Pain Headache Rep; 12: 103-107.

18. Tichelaar V, Geertzen J, Keizer D, van Wilgen PC (2007) Mirror box therapy added to cognitive behavioural therapy in tree chronic complex regional pain syndrome type I patients: a pilot study. Int J Rehab Res; 30: 181-188.

19. Syrjala KL (20II) Relaxation and imagery techniques. In: Loeser JD (ed) Bonica's management of pain. Third edition. Lippincott Williams \& Wilkins, Philadelphia.

20. Woodhouse A (2005) Phantom limb sensation. Clin Exp Pharmacol Physiol; 32: I-2. 
